\title{
High-sensitivity troponin assays and the early rule-out of acute myocardial infarction
}

\author{
Anoop S V Shah, David E Newby, Nicholas L Mills
}

Many patients self-present or are referred by primary care to the emergency department with chest pain because of the potential that they may be suffering an acute myocardial infarction, one of the most common causes of death worldwide. ${ }^{1}$ Owing to diagnostic uncertainty, the majority of these patients are admitted, and, in some centres, chest pain is responsible for up to $40 \%$ of all unplanned hospital admissions. ${ }^{2}$ The majority of these admissions are unnecessary and place additional burden on healthcare systems that are already struggling to cope with increasing emergency care attendances. Approaches to improve the accurate identification of patients with myocardial infarction would therefore be welcome and a potential major benefit.

Cardiac troponins are regulatory muscle proteins that are released into the circulation after acute myocardial injury. Assays that quantify cardiac isoforms of troponin have greater specificity and sensitivity for the diagnosis of myocardial infarction than traditional cardiac enzymes. ${ }^{3}$ Recent advances have led to greatly improved assay sensitivity, permitting quantification of extremely low serum concentrations of troponin with excellent precision. High-sensitivity cardiac troponin assays have limits of detection 10100 -fold lower than contemporary assays and are able to detect troponin in the circulation of the majority of healthy persons. ${ }^{4}$ These assays have the potential to transform how we assess patients with chest pain in the emergency room.

Myocardial infarction is defined as a rise and/or fall in cardiac troponin with at least one value above the 99th centile upper reference limit in the context of symptoms or clinical evidence of myocardial ischaemia. ${ }^{5}$ To minimise the potential for misdiagnosis, the National Institute for Health and Clinical Excellence

BHF/University Centre for Cardiovascular Science, University of Edinburgh, Edinburgh, UK

Correspondence to Dr Nicholas Mills, BHF/University Centre for Cardiovascular Science, Chancellor's Building, Royal Infirmary, Little France, Edinburgh EH16 4SB, UK:

nick.mills@ed.ac.uk
(NICE) guidelines have recommended measuring troponin on admission and 10-12 h after the onset of symptoms to coincide with the peak in circulating troponin concentration. ${ }^{6}$ These guidelines now need updating to reflect the more widespread use of high-sensitivity troponin assays in the clinic. Indeed the latest guidelines from the Global Task Force recommend that troponin concentrations should be determined on admission and at 3-6 $\mathrm{h}$ after admission, irrespective of the timing of onset of symptoms. ${ }^{57}$ More sensitive assays permit the detection of smaller amounts of myocardial injury and therefore enable the clinician to make an earlier diagnosis.

Hoeller and colleagues have addressed an important and clinically relevant question. ${ }^{8}$ Can high-sensitivity troponin assays be used to rule out myocardial infarction with a single measurement of troponin on presentation? This strategy is not endorsed by international guidelines and the answer to the question is unequivocal. Troponin concentrations on presentation were within the normal reference range in up to one-fifth of patients who would subsequently be diagnosed with acute myocardial infarction on repeat sampling. Indeed in patients presenting with symptoms for $<3 \mathrm{~h}$, as many as one in two patients with a diagnosis of myocardial infarction had troponin concentrations within the normal reference range on presentation. In these patients, the diagnosis would have been missed if clinicians were to rely on a single measurement of troponin in the emergency department, and the authors conclude that serial sampling is essential for the diagnosis of myocardial infarction.

One of the strengths of the analysis of Hoeller and colleagues is that they evaluate four high-sensitivity assays including two prototype assays that are not yet commercially available. They report differences between assays in the sensitivity of a single admission troponin concentration for a final diagnosis of myocardial infarction determined on serial testing that, if interpreted incorrectly, could infer advantages or disadvantages of one assay over another. Apparent differences in sensitivity between assays are not due to differences in assay precision, but are a consequence of variance in the manufacturers' recommended 99th centile upper reference limits and the selection of one assay for adjudication of the final diagnosis. The analysis would have been more meaningful if the final diagnosis was adjudicated for each assay in turn or if the upper reference limits, and therefore diagnostic thresholds, were determined for each assay in a single reference population. A recent independent normal reference range study has made a major contribution in this area, reporting upper reference limits that were 3- and 5 -fold higher than the manufacturers' limits for the prototype assays used in the present analysis. ${ }^{9}$ Hoeller and colleagues also highlight the value of standardisation for cardiac troponin assays. We believe all highsensitivity cardiac troponin assays should be evaluated in a large independent, multiethnic, age- and sex-varied reference population to determine the normal range as part of the regulatory approval process.

Serial sampling of troponin is important not just to permit the safe rule-out of myocardial infarction, but also to minimise the potential for misdiagnosis in patients with elevated cardiac troponin concentrations. Improvements in assay sensitivity have inevitably reduced specificity for myocardial infarction, as these assays do not define the cause of myocardial injury. Troponin concentrations may be outwith the normal reference range in patients with other acute illnesses and in patients with chronic structural heart diseases, including stable coronary artery disease ${ }^{10}$ and congestive cardiac failure. ${ }^{11} 12$ It is therefore essential to demonstrate a rise and/or fall in troponin concentration to differentiate acute myocardial infarction from acute or chronic myocardial injury. 57

Innovative algorithms to rule out myocardial infarction in the emergency department based on thrombolysis in myocardial infarction (TIMI) risk score and serial troponin measurement at presentation and $2 \mathrm{~h}$ later may permit an additional $40 \%$ of patients to be safely discharged. ${ }^{13}$ Indeed the use of more sensitive assays and earlier detection of myocardial necrosis does improve clinical outcomes. ${ }^{14}$ The value for the patient, clinician and hospital of a rapid diagnosis is clear, but needs to be offset against the identification of increasing numbers of patients with elevated troponin concentrations due to non-acute coronary syndrome pathologies. ${ }^{15}$ Hoeller and colleagues' use of the manufacturers' recommended upper reference limits, as low as 
$9 \mathrm{ng} / \mathrm{L}$ for two prototype cardiac troponin I assays, highlights the potential for harm. For every patient with an admission troponin concentration $>9 \mathrm{ng} / \mathrm{L}$ correctly diagnosed with myocardial infarction, another patient who did not have acute myocardial infarction was identified. As such, the positive predictive value of an elevated admission troponin concentration was as low as $45 \%$ even in a well-selected population of patients with symptoms suggestive of myocardial infarction. When these assays are used more widely in the emergency department, the use of inappropriate diagnostic thresholds that have not been independently validated have the potential to result in widespread misdiagnosis, unnecessary hospitalisation and investigation, with a detrimental effect on clinical outcomes that may undermine the benefits of an earlier diagnosis of myocardial infarction.

The work of Hoeller and colleagues is important and highlights the need for assay standardisation, robust independent assessment of the normal reference range using an appropriate reference population, and the need for careful evaluation of the impact of high-sensitivity cardiac troponin assays on clinical care.

Contributors All authors contributed to writing the manuscript.

Funding British Heart Foundation Intermediate Fellowship (FS/10/024/28266), Clinical Research Fellowship (SS/CH/09/002 and British Heart Foundation Chair (CH/09/002)).

Competing interests NLM has received honoraria for Abbott Diagnostics and acted as a consultant for Beckman-Coultar and Abbott Diagnostics.

Provenance and peer review Commissioned; internally peer reviewed.

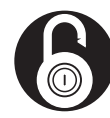

\section{OPEN ACCESS}

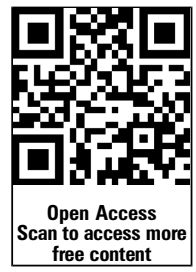

Open Access This is an Open Access article distributed in accordance with the Creative Commons Attribution Non Commercial (CC BY-NC 3.0) license, which permits others to distribute, remix, adapt, build upon this work non-commercially, and license their derivative works on different terms, provided the original work is properly cited and the use is noncommercial. See: http://creativecommons.org/licenses/ by-nc/3.0/

To cite Shah ASV, Newby DE, Mills NL. Heart 2013:99:1549-1550.

Published Online First 17 August 2013



- http://dx.doi.org/10.1136/heartjnl-2013-303643

Heart 2013;99:1549-1550.

doi:10.1136/heartjnl-2013-304033

\section{REFERENCES}

1 World Health Organization. Global status report on noncommunicable diseases 2010. Geneva, 2011:1-176. http://www.who.int/nmh/publications/ncd_report2010/en/

2 Goodacre S, Cross E, Arnold J, et al. The health care burden of acute chest pain. Heart 2005;91:229-30.

3 Keller T, Zeller T, Ojeda F, et al. Serial changes in highly sensitive troponin I assay and early diagnosis of myocardial infarction. JAMA 2011:306:2684-93.

4 Reichlin T, Hochholzer W, Bassetti S, et al. Early diagnosis of myocardial infarction with sensitive cardiac troponin assays. N Engl J Med 2009;361: 858-67.

5 Thygesen K, Alpert JS, Jaffe AS, et al. Third universal definition of myocardial infarction. Eur Heart J 2012:33:2551-67.

6 Cooper A, Timmis A, Skinner J. Assessment of recent onset chest pain or discomfort of suspected cardiac origin: summary of NICE guidance. BMJ 2010;340:c1118.

7 Thygesen K, Mair J, Giannitsis E, et al. How to use high-sensitivity cardiac troponins in acute cardiac care. Eur Heart J 2012;33:2252-7.

8 Hoeller RG, Gimenez MR, Reichlin T. Normal presenting levels of high-sensitivity troponin and myocardial infarction. Heart 2013;99:1567-72.

9 Apple FS, Ler R, Murakami MM. Determination of 19 cardiac troponin I and T assay 99th percentile values from a common presumably healthy population. Clin Chem 2012;58:1574-81.

10 Omland T, de Lemos JA, Sabatine MS, et al. A sensitive cardiac troponin T assay in stable coronary artery disease. N Eng/ J Med 2009;361:2538-47.

11 Newby LK, Jesse RL, Babb JD, et al. ACCF 2012 expert consensus document on practical clinical considerations in the interpretation of troponin elevations: a report of the American College of Cardiology Foundation task force on Clinical Expert Consensus Documents. J Am Coll Cardiol 2012;60:2427-63.

12 Rosjo H, Andreassen J, Edvardsen T, et al. Prognostic usefulness of circulating high-sensitivity troponin $\mathrm{T}$ in aortic stenosis and relation to echocardiographic indexes of cardiac function and anatomy. Am J Cardiol 2011;108:88-91.

13 Cullen L, Muller C, Parsonage WA, et al. Validation of high-sensitivity troponin I in a 2-h diagnostic strategy to assess 30-day outcomes in emergency-department patients with possible acute coronary syndrome. J Am Coll Cardiol 2013. Apr 10. doi:10.1016/j.jacc.2013. 02.078. [Epub ahead of print].

14 Mills NL, Churchhouse AM, Lee KK, et al. Implementation of a sensitive troponin I assay and risk of recurrent myocardial infarction and death in patients with suspected acute coronary syndrome. JAMA 2011;305:1210-16.

15 Mills NL, Lee KK, McAllister DA, et al. Implications of lowering threshold of plasma troponin concentration in diagnosis of myocardial infarction: cohort study. BMJ. 2012;344:e1533. 